\title{
MOOCs Changing Behavior: New Challenges and Issues Leads to Opportunity
}

\author{
Neha Yadava, Mukul Aggarwal ${ }^{b}$, Kamal Kant Sharma ${ }^{c}$, Om Prakash ${ }^{d}$ \\ aDepartment of CSE, KIET Group of Institutions, Delhi NCR Ghaziabad, INDIA \\ ${ }^{b}$ Department of IT, KIET Group of Institutions, Delhi NCR Ghaziabad, INDIA \\ 'Department of IT, KIET Group of Institutions, Delhi NCR Ghaziabad, INDIA \\ ${ }^{\mathrm{d}}$ Department of IT, KIET Group of Institutions, Delhi NCR Ghaziabad, INDIA \\ aneha.yadav@kiet.edu, kamalkant.sharma@kiet.edu, bmukul.aggarwal@kiet.edu, mukul.digital@gmail.com, \\ cnehayadav1508@gmail.com, ${ }^{4}$ om.prakash@kiet.edu
}

Article History: Received: 10 November 2020; Revised 12 January 2021 Accepted: 27 January 2021; Published online: 5 April 2021

\begin{abstract}
Learning through distance mode very helpful for all of us nowadays. MOOCs plays very important roe in all aspects. Govt of India also launch so many platforms for this type of various learning domain. Learning were also early incarnations of various factors depends of nature of learning in the form of written distance learning. MOOCs are a recent development in online education and have several distinctive features compared to previous distance education models. MOOCs are online courses intended for massive interactive participation and free web access. Materials of many conventional course such as power point presentations, online notes, readings, quizzes, and videos. MOOCs provide very interactive and formation of collaborative learning forums that will be very helpful to build community for students and teachers.
\end{abstract}

Keywords: MOOCs, Students, Teachers, blended learning, e-learning resources etc.

\section{Introduction}

Massive MOOCs gain the interest of learners, educators, training providers, institutions and universities. These online courses encourage widespread participation and are open online. A number of initiatives supported by leading universities and colleges, currently primarily in the United States, offer MOOCs in a wide range of fields - psychology, science, computer science, business, mathematics, and allied fields. Some people see online courses as the future of attractive teaching, learning, and work opportunities.

\section{A. Features}

It's massive. The MOOC is designed to enable large numbers of students to enrol online to benefit from their field of work. Now opened. These courses are free for everyone. Anyone around the world can register for the course. On-line. On-line. Delivery, communication and interaction take place over the web. Fine, course. Like a formal course, it carries out an assessment (assignment, quiz, test or exam) and presents certificates to certified learners [2]. When taking a MOOC, it is expected that it will keep pace and that the work will be assessed on a regular basis. While traditional online courses have tuition fees, carry the credit with you and limit enrolment to around 80-90 for better interaction with the e-teacher. MOOCs are generally (currently) free, with no credit, and support massive signups. Since anyone can register for a MOOC course, presentation and functions such as interactivity become more important. MOOC combines education, collaborative learning through forums and social networks, group work and game-based learning [1]. Free (open) online courses are an effective learning environment, especially when compared to large lecture courses. According to MOOCs, online courses enrich oncampus and off-campus learning and deliver the MOOC in other ways [3]. Free MOOCs provide education to large numbers of people, including those in the remotest corners of the universe. A number of areas at various levels are helping students and academics advance their careers and expand their intellectual and personal networks. The breakdown and potential removal of financial, geographic and educational barriers has resulted in an increasing number of learners taking courses online. Global universities are offering a wide range of courses through advanced commercial platforms such as Khan Academy, HarvardX, Udacity and Coursera in 2012 [9]. Learning Analytics (LA) have been used to get the benefit deeper into syllabus and designing of course structures as well part of success and failure of learning [5]. LA itself is an analysis tool that researchers can use to improve and develop their learning strategies in efficient manner. Special features is the ability to analyse the log data from advanced online courses [10]. In the online context, research has shown that most online learners have an inherent rather than an extrinsic motivation [11]. MOOC providers have merged and a huge number of peoples are embracing it. 


\section{B.. MOOC Providers}

Coursera A development at Stanford University, which is currently the largest producer of MOOCs offering over 450 courses.

Udacity It centers around innovation and science. An outgrowth of the Stanford University analyze in which Sebastian Thrun and Peter Norvig offered 'First experience with Artificial Intelligence' online course for nothing out of pocket in which in excess of 160,000 understudies took on in excess of 190 nations[3]. EdX Jointly founded Harvard University and Massachusetts Institute of Technology in the US, it's a non-profit MOOC company that works with several colleges and universities [2][4]. Some providers is organized as a association, with each member institutions maintaining dominion over its MOOC production.

OpenUpEd is the primary Pan-European MOOC activity upheld by the European Commission and incorporates accomplices from 11 nations.

Open2Study The dispatch of Open Universities Australia, main online schooling supplier in a joint effort with a few Australian colleges.

CourseSites Upheld by Blackboard. It is a free, facilitated and versatile internet learning stage. Find and register for the courses.

Khan Academy It expects to offer free, a-list training to anybody anyplace. Its library of more than 4,500 recordings covers science, science, science, material science and humanities, and so forth.

\section{Related Work}

MOOCs enrolled student are divided into two main categories in the existing literature. One is whether the student eventually completes the course and obtains the certificate as a standard of judgment if, without completing and obtaining the certificate, the student withdraws [12]. Massive open online courses (MOOCs) have been emerged from the integration part of the education and the internet both [13]. MOOC learners are not only motivated to take exams involving the understanding of specific concepts or parts of the course content [14].

It is not appropriate to calculate the participation rate. Therefore, the main question behind how "more attractive" is how to reasonably measure the attractiveness of MOOCs. Meanwhile, the smart course platform should help learners study effectively. Thus, the main question about how to be "more effective and wiser" is how to improve learning strategies. With the rapid development of MOOCs, large data is being generated about learning behaviors that enable learners, educators, and researchers to explore the features and mechanisms of online learning [15].

MOOCs as an evolving and emerging model of Internet education, represent a new stage in the development of open educational resources (OER) for students around the worldwide. MOOCs are a self-directed model of Internet education [16]. This educational model offers to the students their free time and course organization and offers opportunities for personalized learning; second thing, there is a stark contrast between higher MOOCs registrations and completion level, which is becoming the problem affecting the learning efficiency of MOOCs [17].

The online review feature of the MOOC platform has become an important resource for MOOC learners to get information about the course, thereby reducing the course uncertainty for the selection process. Usability of MOOCs learners eWOM MOOCs to assess the MOOCs quality and make decisions about registering and learning MOOCs. The effects of eWOM on consumer purchasing behaviour have received wide attention. Studies have shown that eWOM has a major impact on product sales [18]. Openness is the second characteristic of MOOCs, which is reflected in exchange, free access and collaboration [19]. Active learners can be register for MOOCs and participate in MOOCs free of charge in some of the platform [20]. 2012 was a turning point for MOOC research. Most of the research prior to 2012 was based on relevant pedagogical theories, investigating the impact of MOOCs on higher education institutions from a curriculum perspective; Therefore, there was a lack of research on the quality of MOOCs and MOOCs on learning behaviours [21].

After 2012, with the increasing the scenario of internationalization and diversification of MOOCs, selfdetermination theory, social networking theory, and activity theory were gradually applied to in-depth exploration of MOOCs [22]. Thus, now research topic was shifted to MOOC learners' participation, MOOC course completion and the role of social media platforms in MOOC learning [23].

Overall improvement of MOOCs, the quantity of clients on MOOC stages has progressively expanded, however there are not many MOOC students who really complete the courses. Most obviously consummation rates for MOOCs are under 10\% and the general normal fulfilment rate is roughly 5\% [24].

From The viewpoint of individual MOOC students, specialists fundamentally study learning inspiration and learning strategies [25]. A poll overview found that learning revenue was the primary inspiration for students to have MOOCs [26]. For students who don't utilize the MOOCs learning gathering, the quantity of finished students utilizing the MOOCs learning discussion is higher [27]. EEWOM is especially significant for elusive items that 
are hard to assess for shopper decisions; for instance, in the travel industry or lodgings, the general fulfilment of customers will affect the social choices of others [28]. The present situation has made eWOM a more solid medium [29]. Based on the hypothesis of social exchanges, it has been discovered that the level of exertion that buyers need to make to acquire ideal rewards contrarily influences the readiness of shoppers to give praise [30]. The standing of the college has a critical positive effect on the dynamic cycle for people to pick universities [31].

Advanced education for the Indian Government to be among the world's top designing schools, offering courses in information structure, programming and calculations to a great many students through MOOCs. These courses would grant credits and check towards degrees"

\section{New Opportunities And Challenges}

MOOCs bring online conversations and information sharing of thoughts and points of view to more significant levels and scales that are unrealistic in customary study hall game plans. This will ideally bring students from various pieces of the world closer together. MOOC suppliers may offer or offer data to bosses about highperforming understudies who might be Coursera, Udacity and few others, and ongoing news from some prominent innovation organizations have just pursued these services [2]. MOOCs are free somewhere during the COVID, a couple obviously suppliers are searching for achievable plans of action. Allude to this article for potential new plans of action for MOOCs. A couple of open source and free stages are accessible to make MOOCs

\section{A. New challenges with IVR}

MOOCs present difficulties to students, course suppliers and scholastics, students and instructive organizations. It goes from the improvement of courses, changes to showing procedure and learning strategy, inclining materials advancement, understudy execution appraisal and monetary supportability obviously contributions and models, nature of courses and learning, dependable online access and accreditation. IVR innovation is a bunch of cultivating rehearses that are conveyed in an intelligent voice recorded way. According to Voice-Package of Practices, rehearses cover all the difficulties of development, from planting to collecting. The IVRS (Interactive Voice Response System) is utilized to direct up-and-comers bit by bit and to explore the program segments without delay [5][7]. To use MOOCs, Indian instructive establishments and preparing suppliers should be imaginative in building up the correct models to utilize MOOCs in a worldwide setting. Both privately

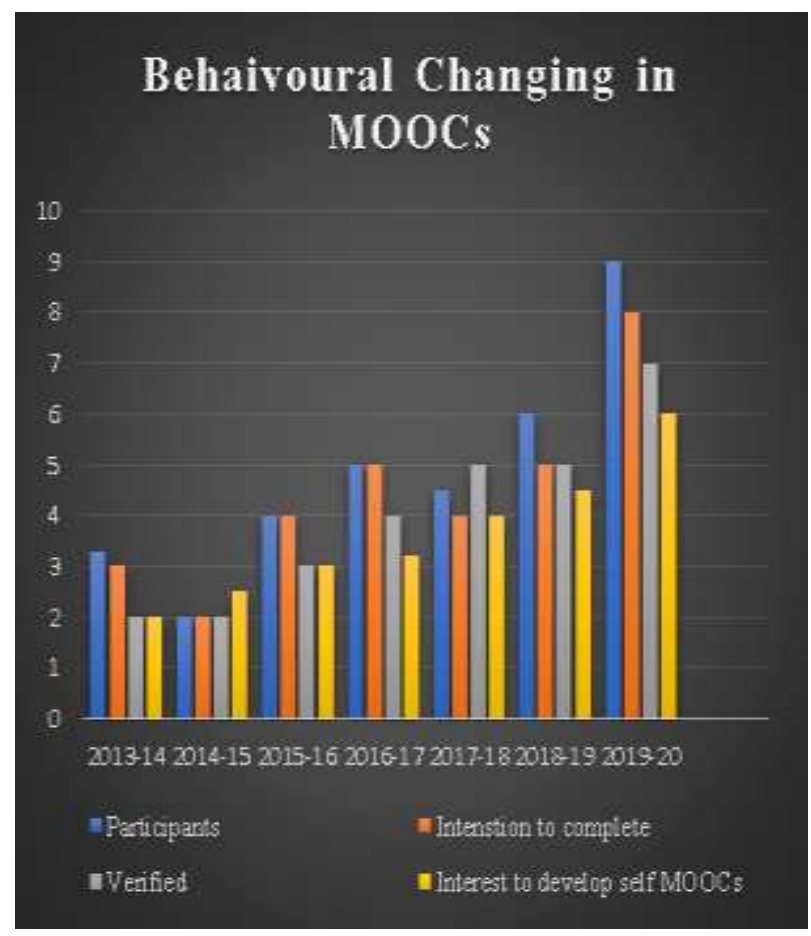

Fig1: Graphical representation for MOOCs behaviour

created MOOCs and famous quality MOOCs gave by top colleges and designers abroad. So many challenges are there in the various forms.

\section{B. Publicity And Reality}

There is currently a lot of hype about MOOCs and expectations in the real scenario. This will work for motivated learners and professionals looking to expand their knowledge and knowledge. By merging in-class 
instruction with quality MOOCs, some of the barriers and limitations of MOOCs may be addressed [6][7]. MOOCs with in-person instructions and support that derive the benefit of both worlds, coupled with certificates offered by institutions, could become an attractive option in the global way that everyone can take advantage of the course.

\section{Student Experience And Outcomes}

There is as of now a great deal of promotion about MOOCs and assumptions in the genuine situation. This will work for propelled students and experts hoping to grow their insight and information. By converging in-class guidance with quality MOOCs, a portion of the hindrances and restrictions of MOOCs might be tended to. The climate wherein MOOCs and different types of online schooling work is changing pretty much consistently [6][7]. MOOCs with in-person directions and backing that determine the advantage of the two universes, combined with endorsements offered by establishments, could turn into an appealing choice in the worldwide manner that everybody can exploit the course.

Table 1. Yearwise MOOCs progress

\begin{tabular}{|l|l|l|l|l|l|}
\hline $\begin{array}{l}\text { Sr } \\
\text { No }\end{array}$ & Year & $\begin{array}{l}\text { Participants } \\
\text { enrolled (\%) }\end{array}$ & $\begin{array}{l}\text { Willingn } \\
\text { ess to } \\
\text { complete } \\
(\%)\end{array}$ & $\begin{array}{l}\text { Verified } \\
(\%)\end{array}$ & $\begin{array}{l}\text { Interest to } \\
\text { develop rolf } \\
\text { MOOCs (\%) }\end{array}$ \\
\hline 1 & $2013-14$ & 3.3 & 3 & 2 & 2 \\
\hline 2 & $2014-15$ & 2 & 2 & 2 & 2.5 \\
\hline 3 & $2015-16$ & 4 & 4 & 3 & 3 \\
\hline 4 & $2016-17$ & 5 & 5 & 4 & 3.2 \\
\hline 5 & $2017-18$ & 4.5 & 4 & 5 & 4 \\
\hline 6 & $2018-19$ & 6 & 5 & 5 & 4.5 \\
\hline 7 & $2019-20$ & 9 & 8 & 7 & 6 \\
\hline
\end{tabular}

\section{A. Learning Design}

MOOCs can improve different sorts of guidance, including mixed learning, eye to eye and internet learning experience for scholastically frail understudies.

Extra help will successfully help understudies and staff to prevail in MOOCs. MOOC additionally advances social and passionate variables for understudies. MOOCs are probably the best stages with scholastically less progressed understudies than others. MOOC models exist for plan segments driving effect for non-selfcoordinated scholastics and extra fold over help should be added to on the web or mixed methodologies.

Institutional, academic, learning plan, innovative and plans of action are presently being utilized. This is important to put forth the most ideal attempt to positively affect our student applicants. MOOCs students who are additionally fit for planning their course and who are free or paid, however the plan of MOOCs is imperative to all students.

\section{Cost And Performance Metrics}

The information recovery from MOOCs is generally useful and can be gotten to and used to propel understudy learning. The expense of MOOCs is connected to improvement, upkeep, guidance and other MOOC tasks. Business engineering is generally compelling for various sorts of establishments and suppliers of MOOC stages. There is a sensible plan of action for MOOCs that centers around healing and basic coursework. Suitable measurements are given to survey the accomplishment of the early on course work of the MOOC understudies. MOOC's drop-out rates contrast and other schooling models (counting, distance training, web-based learning, mixed learning, and in-homeroom learning).

\section{A. MOOCs: Policy And Systemic Impact}

There are such countless elements that have added to the choice of the college to offer the MOOC or to join the MOOC supplier. There are a few models for keeping up and improving MOOC quality. A few measures are utilized by colleges to assess the effect or to characterize the estimation of MOOCs. Department(s) at the college lead or oversee MOOC activities.

\section{B. MOOCs Formats}

Some current innovation suppliers, (for example, Learning Management Systems sellers and distributers) react to MOOCs. MOOC models that unite the achievement of low-pay understudies online with the in-person learning authority. 


\section{Conclusion And Future Scope}

The line among on the web and nearby training is as of now swelling. The University has started to offer acknowledge to understudies for MOOC capabilities and declarations. Era of Jan 2013, Udacity dispatched MOOCs for Credits in a joint effort with San Jose State University in the United States. The Georgia Institute of Technology, in association with Udacity and AT\&T, is offering the first completely licensed MOOC-based Master of Science in Computer Science certificate at a small amount of the expense of an ostensible or free nearby program. MOOCs seem to can possibly draw in business openings, with two significant MOOC suppliers, Coursera and Udacity, dispatched to support organizations. Google, MIT, Georgia Tech and Stanford. Others are putting a huge number of dollars in MOOC and start-up activities. The interruption of the unrest and the converging of new models of schooling and learning

\section{References}

Bell, F. (2011) Connectivism: Its Place in Theory-Informed Research and Innovation in Technology-Enabled Learning. International Review of Research in Open and Distance Learning. Volume 12, Number 3. Retrievable from web http://www.irrodl.org/index.php/irrodl/article/view/902/1664

Robert Zemsky, "With a MOOC MOOC here and a MOOC MOOC there, here a MOOC, there a MOOC, everywhere a MOOC MOOC," Journal of General Education (2014) 63\#4 pp. 237-243 in JSTOR.

http://www.openeducationeuropa.eu/en/paper/moocs-and-beyond

Pappano, aura. "The Year of the MOOC". The New York Times. Retrieved18 April 2014.

Sharma, Yojana (22 April 2013). "Hong Kong MOOC Draws Students from Around the World". Chronicle of Higher Education. etrieved 23 April 2013. reprinted from University World News

P. Adamopoulos, "What Makes a Great MOOC? An Interdisciplinary Analysis of Student Retention in Online Courses", ICIS 2013 Proceedings (2013) pp. 1-21 in AIS Electronic Library (AISeL).

http://agb.org/reports/2013/massive-open-online-courses-moocs-primer-university-and-college-board-members

Booker, Ellis (30 January 2013). "Early MOOC Takes A Different Path". Information Week. Retrieved 25 July 2013.

J. Qiu et al., "Modeling and predicting learning behavior in MOOCs", Proc. 9th ACM Int. Conf. Web Search Data Mining, pp. 93-102, 2016.

D. Gašević, C. Rose, G. Siemens, A. Wolff, and Z. Zdrahal, "Learning analytics and machine learning," in Proc. 4th Int. Conf. Learn. Anal. Knowl. (LAK), 2014, pp. 287-288.

M.-H. Cho and M. L. Heron, "Self-regulated learning: The role of motivation, emotion, and use of learning strategies in students' learning experiences in a self-paced online mathematics course," Distance Educ., vol. 36, no. 1 , pp. 80-99, 2015

R. M. Stein and G. Allione, "Mass attrition: An analysis of drop out from a principles of microeconomics MOOC", Social Sci. Res. Netw., pp. 1-19, 2014.

M. Zhu, A. Sari and M. M. Lee, "A systematic review of research methods and topics of the empirical MOOC literature (2014- 2016)", Internet Higher Educ., vol. 37, pp. 31-39, Apr. 2018.

A. Watted and M. Barak, "Motivating factors of MOOC completers: Comparing between university-affiliated students and general participants", Internet Higher Educ., vol. 37, pp. 11- 20, Apr. 2018.

S. R. Emmons, R. P. Light and K. Borner, "MOOC visual analytics: Empowering students teachers' researchers and platform developers of massively open online courses", J. Assoc. Inf. Sci. Technol., vol. 68, no. 10, pp. 2350-2363, Oct. 2017.

P. M. Moreno-Marcos, C. Alario-Hoyos, P. J. Munoz-Merino and C. D. Kloos, "Prediction in MOOCs: A review and future research directions", IEEE Trans. Learn. Technol., vol. 12, pp. 384-401, Jul. 2019.

D. Gamage, S. Fernando and I. Perera, "Exploring MOOC user behaviors beyond platforms", Int. J. Emerg. Technol. Learn., vol. 15, no. 8, pp. 161-179, 2020.

C. Ruiz-Mafe, E. Bigné-Alca niz and R. Currás-Pérez, "The effect of emotions eWOM quality and online review sequence on consumer intention to follow advice obtained from digital services", J. Service Manage., Jun. 2020.

O. Almatrafi and A. Johri, "Systematic review of discussion forums in massive open online courses (MOOCs)", IEEE Trans. Learn. Technol., vol. 12, no. 3, pp. 413-428, Jul. 2019.

E. J. Delgado-Algarra, I. M. Román Sánchez, E. Ordó nez Olmedo and A. A. Lorca-Marín, "International MOOC trends in citizenship participation and sustainability: Analysis of technical didactic and content dimensions", Sustainability, vol. 11, no. 20, pp. 5860, Oct. 2019.

O. Zawacki-Richter, A. Bozkurt, U. Alturki and A. Aldraiweesh,"What research says about MOOCs-An explorative content analysis", Int. Rev. Res. Open Distrib. Learn., vol. 19, no. 1, pp. 1-18, Feb. 2018.

M. Lan and K. F. Hew, "Examining learning engagement in MOOCs: A self-determination theoretical perspective using mixed method", Int. J. Educ. Technol. Higher Edu., vol. 17, no. 1, pp. 7, Feb. 2020

A. S. Sunar, R. A. Abbasi, H. C. Davis, S. White and N. R. Aljohani, "Modelling MOOC learners' social behaviours", Comput. Hum. Behav., vol. 107, Jun. 2020. 
D. J. Lemay and T. Doleck, "Predicting completion of massive open online course (MOOC) assignments from video viewing behavior", Interact. Learn. Environ., pp. 1-12, Mar. 2020.

Y. Wang and R. Baker, "Grit and intention: Why do learners complete MOOCs?", Int. Rev. Res. Open Distrib. Learn., vol. 19, no. 3, pp. 20-42, Jul. 2018.

M. Zhu, C. J. Bonk and M. Y. Doo, "Self-directed learning in MOOCs: Exploring the relationships among motivation self- monitoring and self-management", Educ. Technol. Res. Develop., pp. 1-21, Feb. 2020.

A. Cohen, U. Shimony, R. Nachmias and T. Soffer, "Active learners' characterization in MOOC forums and their generated knowledge", Brit. J. Educ. Technol., vol. 50, no. 1, pp. 177-198, Jan. 2019.

C.-H. Pai, K.-M. Ko and T. Santos, "A study of the effect of service recovery on customer loyalty based on marketing word of mouth in tourism industry", Revista de Cercetare si Interventie Sociala, vol. 64, pp. 74-84, Mar. 2019.

G. Bae and H.-J. Kim, "Relation between early e-WOM and average TV ratings", Asia Pacific J. Marketing Logistics, vol. 32, no. 1, pp. 135-148, Jun. 2019.

Y. Duan, C. Chen and J. Huo, "The impact of monetary rewards for online reviews", Asia Pacific J. Marketing Logistics, vol. 31, no. 5, pp. 1486-1515, Nov. 2019.

S. Bacci and B. Bertaccini, "Assessment of the university reputation through the analysis of the student mobility", Social Indicators Res., Mar. 2020 